\title{
PLANT SURFACE HIERARCHICAL REPLICAS - A BEHAVIOR IN SELECTED ENVIRONMENTS
}

\author{
1'Dora KROISOVÁ, 2Štěpánka DVOŘÁČKOVÁ \\ 1,2Technical University of Liberec, Liberec, Czech Republic, EU, dora.kroisova@tul.cz
}

https://doi.org/10.37904/nanocon.2019.8552

\begin{abstract}
Hierarchical structures found in nature exhibit specific properties such as low wettability or low reflectance. The aim of this initial study is to present the behaviour of a synthetic hierarchical structure prepared by the replication of plant surfaces, such as from the pansy flower. Natural materials serve their purpose for the necessary time. Synthetic hierarchical structures should be used in technical practice in the long term, for precisely required purposes. However, they do not have self-repairing capabilities, since they are not dynamic but static systems. The polyethylene used to replicate the selected natural structure shows very good results and the prepared replicas match the natural patterns very well. In addition, polyethylene is a commercially available, easy-to-process material with satisfactory mechanical properties. Its disadvantage is easy scratching of the surface. Depending on the material used and the specific nature of the surface structure, different $\mathrm{pH}$ environments $(\mathrm{pH} 5, \mathrm{pH} 9)$ were selected for the evaluation of degradation. Circulating water with quartz sand particles of 20 to 60 microns were selected for surface abrasion simulation. Furthermore, the degradation test of samples in an outdoor environment and evaluation of selected substances adsorption on the sample surface was performed. The degradation processes were monitored and evaluated for 1 month in this initial study. Scanning electron microscopy was used as a basic method for characterization of polymer replicas surface changes.
\end{abstract}

Keywords: Hierarchical structures, plant surface replicas, polyethylene, degradation

\section{INTRODUCTION}

Hierarchical surfaces found in nature are interesting in many ways. Lately, flowers of roses and pansies belong to one of the most studied surfaces that are inspiring for humans as they are able to minimize the reflection of incident radiation [1-3]. At the same time, these structures are highly hydrophobic. Flower surfaces consist of cones with a pentagonal or hexagonal base. The diameter of the cones at the base is usually about 30 to 40 $\mu \mathrm{m}$, the height of the cones reaches 40 to $50 \mu \mathrm{m}$. On the surface of cones are also visible folds with a width of 300 to $400 \mathrm{~nm}$. These structures are referred to in the literature as "light-trapping structures". The flower of the plant thus obtains the maximum amount of energy needed for its growth and development. Hierarchical structures are studied both in terms of their function in plants and their application in technical applications [4, 5]. The pitfalls that emerge from imitating natural structures are related to the fact that plants are living, selfhealing, dynamic systems that serve a given purpose for exactly the required time. If waterdrops fall on the plant's flower, they are removed not only due to the above-described structure covered with natural waxes, but also because of the fact that the leaf or flower bends and the drop rolls off upon impact. Among other things, flowers and leaves grow more often in the vertical direction than in the horizontal direction.

Replicas are currently prepared from different types of polymers, but their stability in real environments [6-8] is not yet evaluated. Replicas made of polyethylene have a highly structured surface [9]. Polyethylene is a material resistant to many chemicals, but its disadvantage is that it is easily scratchable. This paper aims to evaluate the influence of the selected environments on the degradation of synthetically created hierarchical surfaces, which simultaneously include nanostructures, sub-micrometre structures, and microstructures and are prepared from a non-polar material - high-density polyethylene. 


\section{EXPERIMENTAL PART}

\subsection{Materials}

Pansy flower surface, which is characterized by a hierarchical structure of epidermal cells at micrometre and sub-micrometre levels, was selected for the process of replication. The pansy flower conical cells show a diameter of approximately 30 to $40 \mu \mathrm{m}$ at the base, wrinkles on top of epidermal cells and folding typical for all cultivars of a pansy. Clearly visible folds show thickness from 300 to $400 \mathrm{~nm}$. The epidermal cells height is about $40 \mu \mathrm{m}$. High-density polyethylene HDPE (Goodfellow $\mathrm{GmbH}$ ) was used for the preparation of petal surface polymer replicas. A two-step replication process was used to prepare the petal surface polymer replicas. Citric acid p. a. (Fisher Scientific), sodium hydroxide p. a. (Fisher Scientific) was used to adjust the $\mathrm{pH}$ of the test solutions. Quartz sand particles having a diameter in the range of 20 to $60 \mu \mathrm{m}$ in distilled water at a concentration of $1 \%$ by weight were selected to assess the degradation of the samples by abrasion in an aqueous medium.

\subsection{Degradation of samples}

Polyethylene specimens with replicated surface hierarchical structures were placed in several selected environments - different $\mathrm{pH}$ environments, abrasive particles, and real outdoor environments. Adjustment to $\mathrm{pH} 5$ was performed with citric acid, to $\mathrm{pH} 9$ with sodium hydroxide. The temperature of the solutions was $23 \pm 2{ }^{\circ} \mathrm{C}$. Another degradation medium was distilled water with $1 \mathrm{wt}$. silica sand particles having a size in the range of 20 to $60 \mu \mathrm{m}$. The particulate water was stirred in a beaker with a magnetic stirrer. The speed was 300 rpm, the water temperature was $40{ }^{\circ} \mathrm{C}$, the bath was heated and not cooled. Another set of samples placed on a Petri dish was exposed to the normal environment for 1 month from the $18^{\text {th }}$ of July to the $18^{\text {th }}$ of August. Temperatures in this period ranged from $15^{\circ}$ to $40^{\circ} \mathrm{C}$. In this period, samples were exposed to normal sunlight, rain, dust particles or mildew spores.

\subsection{Evaluation of samples degradation}

Samples were investigated by scanning electron microscopy (FE SEM Zeiss ULTRA Plus). All samples were sputter-coated with a $3 \mathrm{~nm}$ Pt-Pd layer (Quorum Q150R ES) before SEM investigation. The static contact angle was determined at See System E. $5 \mu$ ldroplets of distilled water were applied to the surface replicas.

\section{RESULTS AND DISSCUSSION}

High-density polyethylene replicas create a very good image of the natural pattern. Electron microscope images clearly show the conical shape of the epidermal cells, the diameter, the height of the cells, the hexagonal bases of these cells, their interconnection and folds on the surface of cells at the level of hundreds of nanometres. Besides, a fine fibrillar structure is visible on the surface of the folds and is transversally mounted to this surface. The dimensions of the fibres forming this structure range from 10 to $20 \mathrm{~nm}$ Figure 1. This initial study aimed to assess the influence of selected degradation environments on the hierarchical structure generated by the natural pattern replication process. All samples were evaluated both after their preparation and after exposure in selected environments. Scanning electron microscope sample evaluation did not reveal any major changes in the hierarchical structure after the degradation process. The exception was the grinding of cones in an abrasive environment. However, by measuring the wettability or determining the contact angle values, changes due to the degradation environment were identified. Changes in the chemical composition of the polymer surface were not evaluated in more detail in this work because no air conditioning chamber was used. 

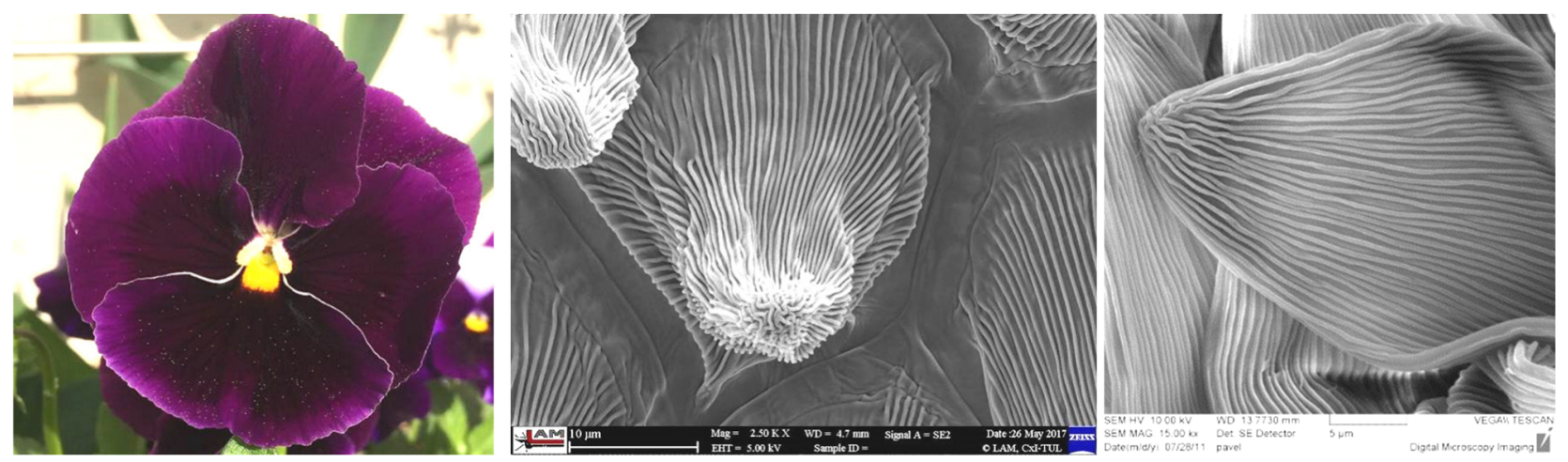

Figure 1 Pensy (Viola $x$ wittrockiana) - the natural petal surface. The hierarchical structure of dried epidermal conical cells of pansy and dried natural petal surface $[9,10]$

The surface of pansies, or the natural sample used in this experiment, is characterized by a specific hierarchical structure. A thin layer of epidermal cone cells with a minimum water content was removed from the flower surface - Figure 1. Due to the high water content in all plant samples in general, they undergo considerable deformation due to water loss when dried before electron microscope insertion.
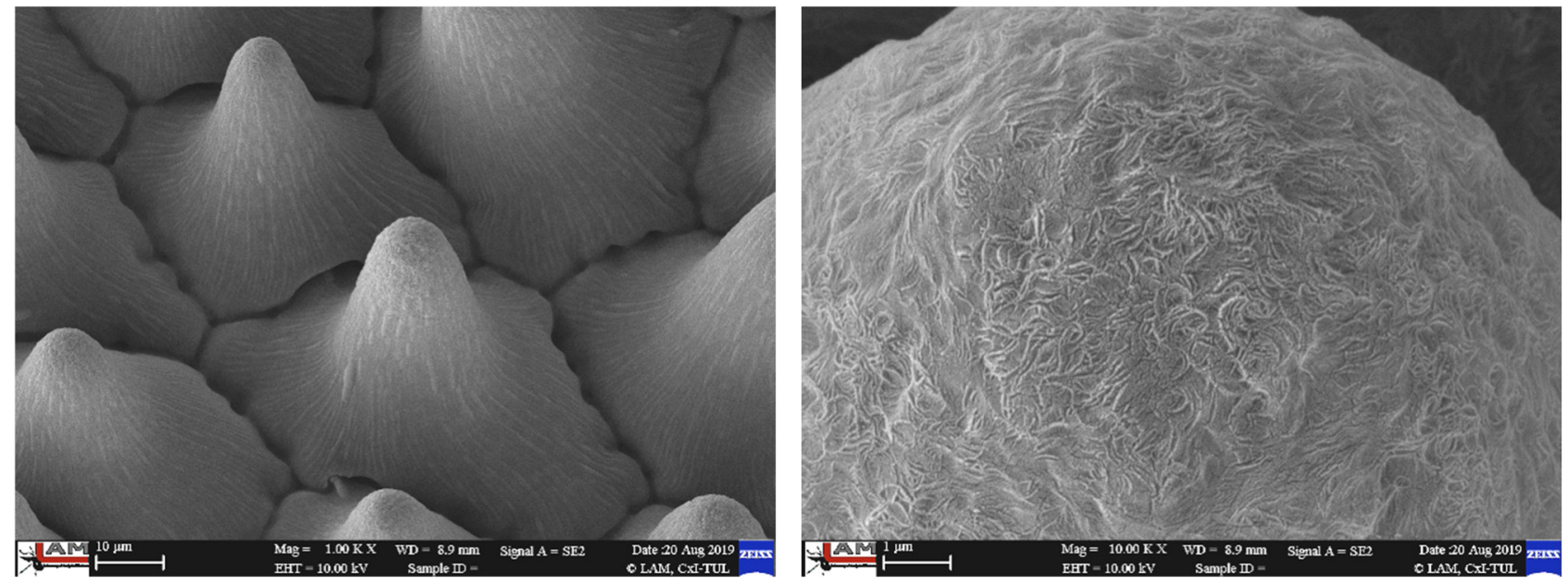

Figure 2 PE replica surface of a pansy flower after sample preparation - overview and detailed image of the surface with characteristic substructure

The replica surface of a pansy flower shows excellent resemblance to its natural pattern. Besides, it has a substructure that is missing from the natural pattern. The substructure is made up of fibrous formations at the level of tens of nanometres - Figure 2. Pansy flower surfaces, as well as their replicas, are non-wettable. The contact angle for the natural pattern is $140^{\circ}$, for replicas made of high-density polyethylene $138^{\circ}$. In both cases, hydrophobic behaviour is ensured simultaneously by structure and chemical composition. The contact angle measured for high-density polyethylene without structured surface is $77^{\circ}$. Samples exposed to different $\mathrm{pH}$ environments do not cause changes to be observed by scanning electron microscopy, either in the substructure or surface storage area - Figure 3. However, there is a change in wettability, in a pH 5 environment the contact angle decreases by $5.8 \%$, pH 9 decreases by $9.4 \%$ - Table 1.

Within one month, degradation of samples was performed by abrasion of the surface of replicas prepared from high-density polyethylene. Since polyethylene is a soft material, surface destruction occurred very quickly, in a matter of hours after insertion into the test solution. As can be seen from the images presented, the surface portion of the cones wears while the substructure is retained - Figure 4. At the same time, the wettability has 
changed, the contact angle decreased by $92.7 \%$ and more. During the test, the temperature increased from $23^{\circ} \mathrm{C}$ to $40^{\circ} \mathrm{C}$. This temperature is not essential for the destruction of the samples used. The melting point of the high-density polyethylene is above $100^{\circ} \mathrm{C}$. This temperature was not reached in the experiment. No sand particles were found to be used as abrasives in any of the scanned images.
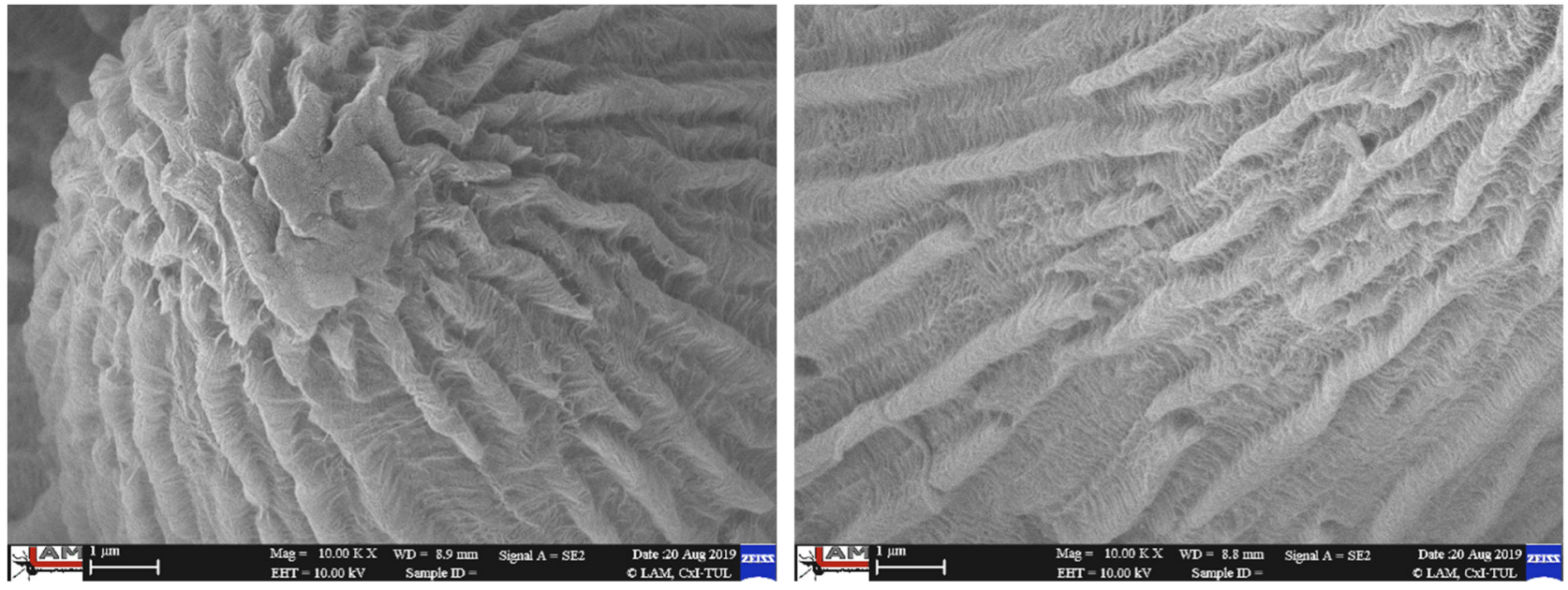

Figure $3 \mathrm{PE}$ replica surface of a pansy flower after monthly exposure in $\mathrm{pH} 5$ (left) and pH 9 (right) environments - detailed surface images with substructure characteristic of the replica

Within one month, degradation of samples was performed by abrasion of the surface of replicas prepared from high-density polyethylene. Since polyethylene is a soft material, surface destruction occurred very quickly, in a matter of hours after insertion into the test solution. As can be seen from the images presented, the surface portion of the cones wears while the substructure is retained - Figure 4. At the same time, the wettability has changed, the contact angle decreased by $92.7 \%$ and more. During the test, the temperature increased from $23^{\circ} \mathrm{C}$ to $40^{\circ} \mathrm{C}$. This temperature is not essential for the destruction of the samples used. The melting point of the high-density polyethylene is above $100^{\circ} \mathrm{C}$. This temperature was not reached in the experiment. No sand particles were found to be used as abrasives in any of the scanned images.
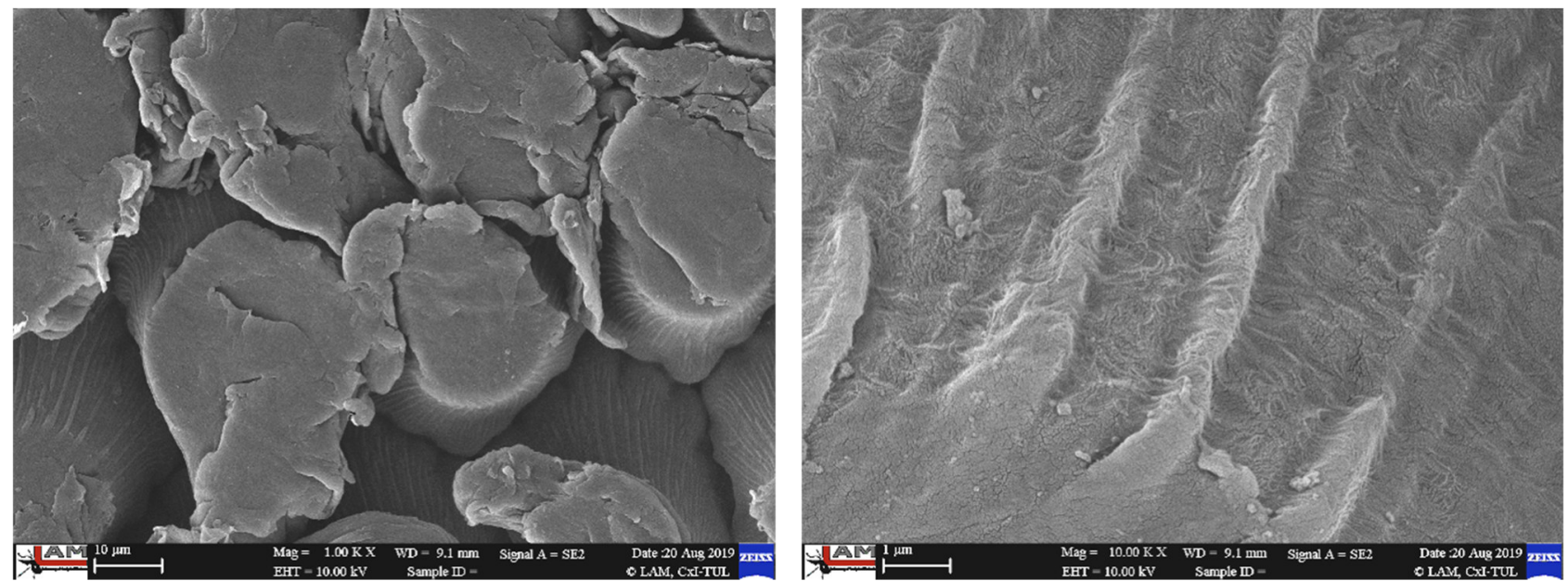

Figure 4 PE replica surface of a pansy flower after monthly exposure in an abrasive environment - overview and detailed image of the surface with characteristic substructure

Evaluation of degradation of a sample in real natural environment showed that there was no change of the microstructure and thus the cones warehouse, or to change substructures. Electron microscope images show 
the presence of micrometre particles on the surface of the replica. The substructure on the surface shows that it has not broken despite the dimensions in nanometre units - Figure 5.
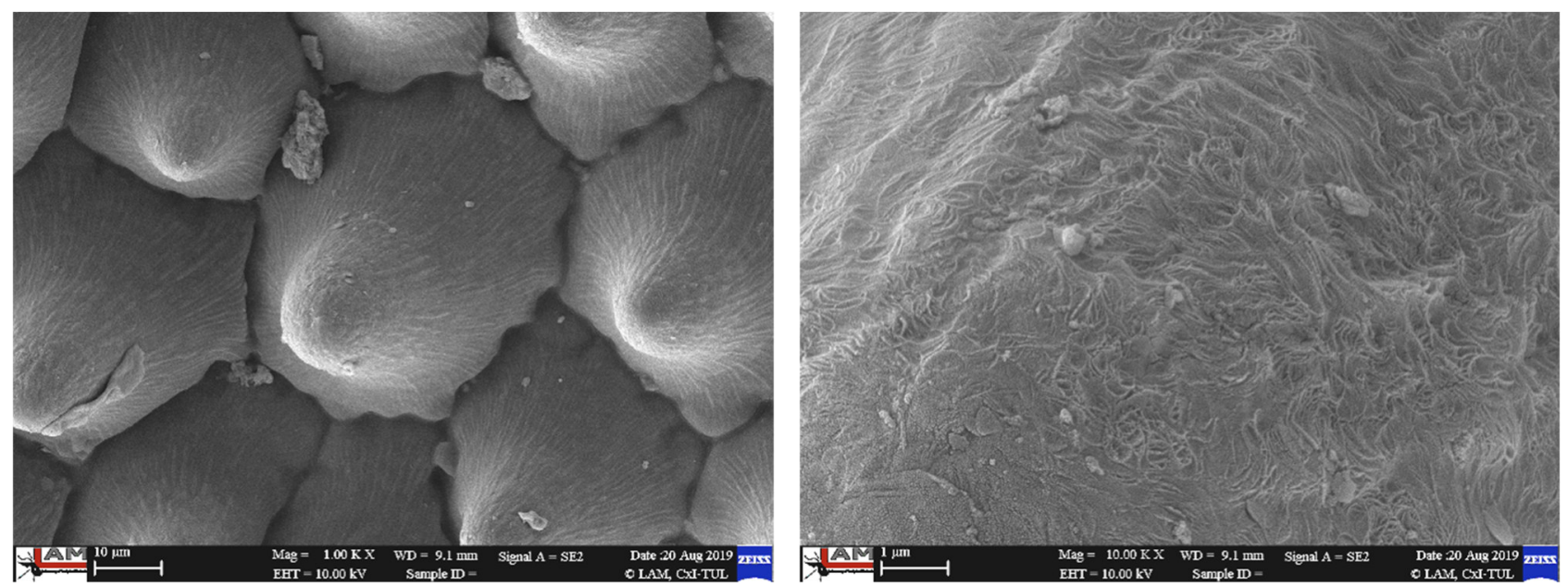

Figure 5 PE replica surface of a pansy flower after monthly exposure in a real environment - overview and detailed image of the surface with characteristic substructure

The evaluation of the contact angle shows a significant decrease of $56.5 \%$. This reduction is probably related to the degradation of the material at the supra-molecular level. Sample degradation is related to the environment that has been applied to the samples for 1 month. Comparing the temperatures to which the samples were subjected in this and previous measurements, it is likely that a slightly elevated temperature will not cause material degradation. The degradation will be caused by solar radiation, which in the first phase is manifested by a change in hydrophobicity.

Table 1 Contact angle of plant pattern and structured polymer replicas before degradation and after a month of degradation

\begin{tabular}{|c|c|c|c|}
\hline Samples & $\begin{array}{c}\text { Contact angle } \\
\text { of replica surface } \\
\text { before degradation } \\
\left({ }^{\circ}\right)\end{array}$ & $\begin{array}{c}\text { Contact angle } \\
\text { of replica surface } \\
\text { after degradation } \\
\left({ }^{\circ}\right)\end{array}$ & $\begin{array}{c}\text { Decrease } \\
\text { of contact angle } \\
(\%)\end{array}$ \\
\hline Plant pattern - Viola x wittrockiana & 140 & non relevant & non relevant \\
\hline HDPE replica - pH5 & 138 & 130 & 5.8 \\
\hline HDPE replica - pH 9 & 138 & 125 & 9.4 \\
\hline HDPE replica - abrasion in water & 138 & 10 and less & 92.7 and more \\
\hline HDPE replica - environmental condition & 138 & 60 and less & 56.5 and more \\
\hline
\end{tabular}

\section{CONCLUSION}

These measurements show that the prepared and described samples do not withstand the degradation processes. This degradation in the first approximation resulted in a change in the wettability of the sample surfaces and the hydrophobic surface became hydrophilic. Assessment of the chemical changes that occurred was not performed in this experimental study because the samples were exposed to the outdoor environment and the sunshine hours, temperature, humidity, cycles, and their numbers were not precisely defined. The degradation of polymer samples with a hierarchical structure is evident and is probably strongly conditioned 
by the existing large specific surface area. At the moment, many works are focused on the creation of replicas, so this issue should be examined in more detail.

\section{ACKNOWLEDGEMENTS}

This work was supported by the Ministry of Education, Youth and Sports of the Czech Republic and the European Union - European Structural and Investment Funds in the frames of Operational Programme Research, Development and Education - project Hybrid Materials for Hierarchical Structures (HyHi, Reg. No. CZ.02.1.01/0.0/0.0/16_019/0000843). My thanks belong to Martin Švec for microscopic analysis.

\section{REFERENCES}

[1] BHUSNAN, B., JUNG, Y.C. and KOCH, K. Micro-, nano- and hierarchical structures for superhydrophobicity, selfcleaning and low adhesion. Philosophical Transactions of the Royal Society A: Mathematical, Physical and Engineering Sciences. 2009. vol. 367, no. 1894, pp. 1631-1672.

[2] SCHULTE, A. J. Light-trapping and Superhydrophobic Plant Surfaces - Optimized Multifunctional Biomimetic Surfaces for Solar Cells. Bonn: Rheinischen Friedrich-Wilhelms-Universitat Bonn. 2012. pp. 113.

[3] HUANG, Z., YANG, S., ZHANG, H., CAO, W. Replication of Leaf Surface for Light Harvesting. Scientific Reports. 2015. vol. 5, no. 14281.

[4] HUANG, Z., CAI, C., KUAI, L., LI, T. HUTTULA, M., CAO, W. Leaf-structure patterning for antireflective and selfcleaning surfaces on Si-based solar cell. Solar Energy. 2018. vol. 159, pp. 733-741.

[5] SCHULTE, A. J., MAIL, M., HAHN, L. A., BARTHLOTT, W. Ultraviolet patterns of flowers revealed in polymer replica - caused by surface architecture. Beilstein J. Nanotechnol. 2019. Vol. 10, 459-466.

[6] CHARCHIT, K., LE HOUÉROU, V., SPECK, T., BOHN, H.F. Straightforward and precise approach to replicate complex hierarchical structures from plant surfaces onto soft matter polymer. R. Soc. open sci. 2018. Available from: https://doi.org/10.1098/rsos.172132.

[7] FRITZ, B., GUTTMANN, M., SOLER, P.C., ROSLIZAR, A., LANGENHORST, M., SCHNEIDER, M., PAETZOLD, W.U., RICHARDS, B. S., LEMMER, U., HUENIG, R., GOMARD, G. Towards mass fabrication of hot embossed plant surface texture replicas as photovoltaic cover layers. In Proc. SPIE Nanoscience + Engineering. San Diego: 2018, Available from: https://doi.org/10.1117/12.2320555.

[8] NAGATO, K. Injection Compression Molding of Replica Molds for Nanoimprint Lithography. Polymers. 2014. vol. 6, pp. 604-612. Available from: https://doi.org/10.3390/polym6030604.

[9] KROISOVA, D. Natural Hierarchical Structures and Their Replication. In NANOCON 2018: 10th Anniversary International Conference on Nanomaterials - Research and Application. Ostrava: TANGER, 2018, pp. 306-311.

[10] KROISOVA, D. Microstructures and Nanostructures in Nature. In: Emil Wolf ed. Progress in Optics. 2012, chapter 2, pp. 93-132. 